\title{
Total organic carbon in soils and its relation with manganese concentrations in soils and vegetation close to an abandoned manganese mine
}

\author{
${ }^{1 *}$ G. I. E. Ekosse, ${ }^{2}$ P. S. Fouche and ${ }^{2}$ B. Mashatola
}

${ }^{1} X$-Ray Diffraction Unit, Faculty of Science, University of Botswana, Botswana

${ }^{2}$ School of Agricultural and Environmental Science, University of Limpopo, South Africa

Received 31 January 2005;

revised 5 February 2006;

accepted 3 March 2006

available online 18 April 2006

\begin{abstract}
This study aimed at quantifying the total organic carbon (TOC) present in soils within the proximity of the Kgwakgwe Mn oxide ore abandoned mine, Botswana, and establish its relationship with Mn concentrations in soils and vegetation based on multivariate and Geographical Information Systems (GIS) analytical techniques. Four hundred soil samples and 200 vegetation set samples were obtained from a $4 \mathrm{~km}^{2}$ area close to the abandoned mine. The TOC in soil samples were determined using a carbon/hydrogen/moisture determinator, and Mn concentrations in soils and vegetation by atomic absorption spectrophotometry. Results were processed using the statistical package for social science (SPSS), GIS, and Remote Sensing (RS) techniques with the Integrated Land and Water Information System (ILWIS), Geosoft Oasis Montaj and ArcGIS software packages. The values for TOC in the soil samples from the study area ranged from $0 \mathrm{wt} \%$ to $7.91 \mathrm{wt} \%$, with a mean of $1.90 \mathrm{wt} \%$, and at the control area, from $4.07 \mathrm{wt} \%$ to $4.86 \mathrm{wt} \%$. The range of concentrations of $\mathrm{Mn}$ in soils was from $36 \mathrm{mg} / \mathrm{g}$ to $24908 \mathrm{mg} / \mathrm{g}$ and for Mn concentrations in the vegetation samples from $26 \mathrm{mg} / \mathrm{g}$ to $3611 \mathrm{mg} / \mathrm{g}$ with a mean of $598 \mathrm{mg} / \mathrm{g}$. Results of correlation coefficients depicted very weak negative association except $\mathrm{Mn}$ in soils/Mn in leaves which was weak but positive. The statistical data yielded four clusters as follows: cluster one consisted mainly of $\mathrm{Mn}$ in leaves, cluster two was constituted of $\mathrm{Mn}$ in soils, and cluster four had TOC. Cluster three was dominated by the three parameters but with negative t statistic. The spatial presentation of data presented revealed little or no vegetation in the south eastern area and those close to the mine workings, and some significant vegetation in the north western part of the study area. The low TOC in the soils is associated to low vegetation cover which is considered to have been influenced by the soil clay fraction mineralogy and high concentrations of $\mathrm{Mn}$.
\end{abstract}

Key words: Bonferroni adjusted clustering, cluster analysis, image processing, spatial presentation

*Corresponding Author, E-mail:ekossege@mopipi.ub.bw

\section{INTRODUCTION}

The use of multivariate analyses and geographical information system (GIS) techniques in understanding different physical environments in Botswana has been limited to clays and clay minerals (Ekosse and Forcheh, 2005), Mn concentrations in soils and vegetation (Ekosse and Fouche, 2005, 2005a) and nickel-copper deposit (Ekosse et al, 2005). Both techniques have not been applied to establish statistical relationship among total organic carbon (TOC) in soils, Mn concentrations in soils and $\mathrm{Mn}$ concentrations in vegetation. Kgwakgwe soils are moderate, moderate-well to well drained, having brown to yellowish brown colour, and sandy loam to sandy clay texture (Mitchell, 1976; Remmelwaal, 1988). Kgwakgwe vegetation is dominated by acacia plants which include Acacia tennispina, Acacia mellifera, Acacia karoo, Acacia hereroense,
Acacia caffra and Acacia tortills, and other dominant species are Combretum apiculatum, Euclea undulata and Terminalia sericea (Timberlake, 1980). The soil lithology and vegetation type of the study site $(2 \mathrm{~km} \mathrm{x}$ $2 \mathrm{~km}$ ) and the control site were very similar. The control site of $900 \mathrm{~m}^{2}$ (300 m x $300 \mathrm{~m}$ ), separated by a paleotopographic barrier devoid of Mn mineralization, located $4 \mathrm{~km}$ south of the studied area, was chosen (Ekosse and Vink, 1998). Manganese was mined at Kgwakgwe (latitudes $24^{\circ} 59^{\prime}$ and $25^{\circ} 02^{\prime}$, and longitudes $25^{\circ} 17^{\prime}$ and $25^{\circ} 20^{\prime}$ ), south eastern Botswana from 1957 to 1987 (Ekosse, 2001; Ekosse and Mulaba-Bafubiandi, 2003; Ekosse and Nkoma, 2002; Ekosse and Vink, 2001; Lanzincka, 1992). However, no rehabilitation of mine sites was effected at the abandonment of the mining project (Ekosse and Fouche, 2005). Consequently, the 
possibility of high $\mathrm{Mn}$ in soils affecting the $\mathrm{Mn}$ concentrations in vegetation thereby causing sparse vegetation cover within Kgwakgwe may not be ignored. Linked to this suspected phenomenon is the relationship of TOC to the environment. This study therefore addressed the association of $\mathrm{Mn}$ concentrations in soils and vegetation in relation with the TOC in soils close to the abandoned mine. It was carried out by investigating the statistical relations of these parameters in the soils and vegetation, based on a multivariate statistic approach. It attempted to elucidate on environmental mining impact on the TOC in soils and the spatial distribution of the vegetation of the study area.

\section{MATERIALS AND METHODS}

Soils and vegetation sampling and samples

The techniques and methods for soil sampling as described by Jewell et al., (1993), Crépin and Johnson (1993) and Tan $(1996,1998)$ were used to obtain soil samples from both the study area and the control site. Four hundred soil samples were taken at $100 \mathrm{~m}$ intervals, and at a depth of between $0 \mathrm{~cm}$ and $20 \mathrm{~cm}$, nine samples from the control site for analyses. Vegetation sample sets obtained at alternate soil sample points consisted of leaves from Combretum apiculatum, Euclea undulata and Terminalia sericea. Mature dark green leaves with leaf diameter ranging from $2 \mathrm{~cm}$ to $4 \mathrm{~cm}$ within both the study and control sites were harvested for laboratory analyses. Between 100 and 200 leaves depending on the leaf diameter, which constituted a sample set, were sampled per sampling area. Two hundred vegetation set samples were obtained at 200 $\mathrm{m}$ intervals and four vegetation sets of samples from the control site.

\section{Laboratory analyses}

The TOC contents in soil samples were determined using a LECO RC-412 multiphase Carbon/Hydrogen/ Moisture Determinator. The principle is based on converting all $\mathrm{C}$ to $\mathrm{CO}_{2}$ in an oxidising analytical atmosphere. The organic form of $\mathrm{C}$ produces both $\mathrm{H}_{2} \mathrm{O}$ and $\mathrm{CO}_{2}$, which enables TOC to be measured from observable $\mathrm{H}_{2} \mathrm{O}$ peaks. The quantitative analysis program was set for the time and temperature required, which is thirty minutes at $125^{\circ} \mathrm{C}$, after qualitative tests were conducted to obtain the ranges. Manganese concentrations in the samples were determined by atomic absorption spectrophotometry after acid digestion. The procedure for sample digestion is as reported by Jones and Case (1990) and Page et al., (1982).

\section{Multivariate analyses and GIS techniques}

The data was processed with the aid of the SPSS software, and statistical multivariate analyses as explained Page et al., (1982) were performed. The analyses included descriptive statistics, frequency tables, Pearson's correlation matrix, Chi-square or ttest of significance for $95 \%$ confidence levels, the Bonferroni adjusted two-step cluster analysis, and hierarchical clustering. Laboratory results were processed with the Integrated Land and Water Information System (ILWIS), Geosoft Oasis Montaj (version 4.2) and Arc GIS software packages. The TOC data were processed and analysed quantitatively. Geosoft Oasis Montaj was used to prepare gridded map which served as the base map. Image enhancement techniques contrast stretching and image filtering was applied to data to improve visual interpretation. Aquickbird $2.4 \mathrm{~m}-2.8 \mathrm{~m}$ resolution with zero cloud cover multispectral standard imagery of the study area was processed to establish the vegetation cover. The vegetation cover was determined using the Normalised Difference Vegetation Index (NDVI) (ILWIS 3.0, 2002; Principles of Remote Sensing, 2000), which is calculated as follows:

NDVI $=($ Infrared - red $) /($ Infrared + red $)=($ band $4-$ band 3$) /$ (band 4 + band 3 )

Where NDVI values range from -1 to 1 (Principles of remote sensing, 2000). The NDVI assumes isovegetation lines converge at origin and all bare soil in an image will form a hypothetical line in spectral space known as the soil with zero vegetation. Green vegetation yields high values for the ratio whilst in contrast water yields negative values and bare soils give near zero values. The NDVI which works best at $>30 \%$ vegetation cover (Principles of Remote Sensing, 2000; Erdas Imagine, 1992) was used to do the overlays. The study area definitely had enough vegetation cover for the effective application of NDVI technique. The NDVI compensates for changes in illumination, surface slope and aspect.

\section{RESULTS}

\section{TOC and Mn concentrations}

The results of laboratory analyses for TOC in soil samples, and Mn concentrations in both soils and vegetation are presented in samples Tables 1 and 2 and Fig. 1. Values obtained for TOC in soil samples from both the study site and the control area ranged from $0 \mathrm{wt} \%$ to $7.91 \mathrm{wt} \%$, with a mean of $1.90 \mathrm{wt} \%$. At the control area, the TOC in the soil samples ranged from 4.07 wt \% to 4.86 wt \% (Tables 1 and 2). The TOC values obtained for soil samples at the control site were 
significantly higher than the mean TOC value for soil samples from the study site. The range of concentrations of $\mathrm{Mn}$ in soils from the study area was from $36 \mu \mathrm{g} / \mathrm{g}$ to $24908 \mu \mathrm{g} / \mathrm{g}$ with a mean of $1089 \mu \mathrm{g} / \mathrm{g}$; and in the control area was from $62 \mu \mathrm{g} / \mathrm{g}$ to $763 \mu \mathrm{g} / \mathrm{g}$; and these values were significantly lower than the mean concentration values of soils from the study site (Ekosse and Fouche, 2005). The Mn concentrations in the vegetation samples from the study area was from $26 \mu \mathrm{g} / \mathrm{g}$ to $3611 \mu \mathrm{g} / \mathrm{g}$ with a mean of $598 \mu \mathrm{g} / \mathrm{g}$; and in the control area was from $131 \mu \mathrm{g} / \mathrm{g}$ to $324 \mu \mathrm{g} / \mathrm{g}$; and these values were also significantly lower than the mean concentration values of soils from the study site (Ekosse and Fouche, 2005a).

\section{Inferential statistics and multivariate analysis}

The product moment correlation coefficients among the TOC, Mn concentrations in soils and $\mathrm{Mn}$ concentrations in leaves are shown in Table 3. In general, the correlation coefficients depicted very weak leaves, and Fig. 2 reflects their $95 \%$ simultaneous confidence intervals for their means. Coded values (110) which are used in the clusters are based on real values shown in Table 1. Four clusters were obtained, and their interpretations are based on the mean values obtained for each parameter. Cluster one was characterized by Mn concentrations in leaves, cluster two by Mn concentrations in soils, and cluster four by TOC in soils. Cluster three was characterized by none of the three parameters. Figs. 3 is the Bonferroni Adjustment "by variable" importance charts for two step cluster analysis for TOC in soil samples, Mn concentrations in soil samples, and Mn concentrations in vegetation samples. The variables are lined up on the $\mathrm{Y}$ axis, in descending order of importance. The dashed vertical lines mark the critical values for determining the significance of each variable. For a variable to be considered significant, its $t$ statistic must exceed the dashed line in either a positive or negative direction. A negative $t$ statistic indicates that the variable generally takes smaller than average values within this

Table 1: Frequency tables of manganese in leaves and soils and TOC of soil samples

\begin{tabular}{|c|c|c|c|c|c|c|}
\hline Code & $\begin{array}{c}\text { Mn in leaves } \\
(\mu g / g)\end{array}$ & $\mathrm{F}$ & $\begin{array}{c}\text { Mn in soils } \\
(\mu g / g)\end{array}$ & $\mathrm{F}$ & $\begin{array}{c}\text { TOC } \\
\text { (wt \%) }\end{array}$ & $\mathrm{F}$ \\
\hline 1 & $0-299.99$ & 57 & Below 200.00 & 137 & $0-0.99$ & 127 \\
\hline 2 & 300.0-599.99 & 67 & $200.01-500.00$ & 119 & $1.00-1.99$ & 125 \\
\hline 3 & 600.0-899.99 & 42 & 500.01-1000.00 & 54 & $2.00-2.99$ & 60 \\
\hline 4 & 900.0-1199.99 & 18 & 1000.01-1500.00 & 23 & $3.00-3.99$ & 44 \\
\hline 5 & 1200.0-1499.99 & 7 & $1500.01-2000.00$ & 12 & 4.00-4.99 & 36 \\
\hline 6 & 1600.0-1799.99 & 2 & 2000.01-2500.00 & 16 & Above 6.0 & 8 \\
\hline 7 & 1800.0-2099.99 & 2 & 2500.01-3000.00 & 6 & & \\
\hline 8 & 2100.0-2399.99 & 1 & Above 3000.01 & 33 & & \\
\hline 9 & 2400.0-2699.99 & 1 & & & & \\
\hline \multirow[t]{2}{*}{10} & Above 2700 & 3 & & & & \\
\hline & Total & 200 & Total & 400 & Total & 400 \\
\hline
\end{tabular}

Table 2: Descriptive statistics of manganese in leaves and soils and TOC of soil samples

\begin{tabular}{llll}
\hline Parameter & Mn in leaves & Mn in soils & TOC \\
\hline Mean & 2.49 & 2.73 & 2.40 \\
Std. Error of Mean & 0.117 & 0.105 & 0.069 \\
Median & 2.00 & 2.00 & 2.00 \\
Mode & 2 & 1 & 1 \\
Std. Deviation & 1.656 & 2.108 & 1.371 \\
\hline
\end{tabular}

associations. The TOC/Mn in soils and TOC/Mn in leaves depicted very weak correlation reflecting weak negative associations. The $\mathrm{Mn}$ in soils/Mn in leaves portrays weak positive association. Table 4 gives the cluster profile of TOC in soil samples, Mn concentrations in soils and $\mathrm{Mn}$ concentrations in
Table 3: Pearson correlation test for manganese in leaves and soils and TOC of soil samples

\begin{tabular}{lccc}
\hline \multicolumn{1}{c}{ Parameter } & $\begin{array}{c}\text { Mn in } \\
\text { leaves }\end{array}$ & Mn in soils & $\begin{array}{c}\text { TOC } \\
\text { (wt \%) }\end{array}$ \\
\hline Mn in leaves & 1 & & \\
Mn in soils & .056 & 1 & \\
TOC (wt \%) & -.081 & $-.170(*)$ & 1 \\
\hline
\end{tabular}

*Correlation is significant at the 0.01 level (2-tailed).

cluster, while a positive $t$ statistic indicates the variable takes larger than average values. Cluster one shows Mn concentrations in leaves and TOC in soils exceeding the critical value (Fig. 3a). The negative $t$ statistic for TOC indicates that the variable generally take smaller than average values within this cluster. For the formation 
E. Ekosse, et al.

of cluster two, Mn concentrations in soils, was the only important parameter, and with a positive $t$ statistic value obtained for it (Fig. 3b). In cluster three, the importance measures for the three parameters exceed the critical value, and were all having negative $t$ statistic values (Fig. 3c). In cluster four, TOC was the most important followed by Mn concentrations in soils and to a lesser extent, Mn concentrations in leaves. However, only TOC
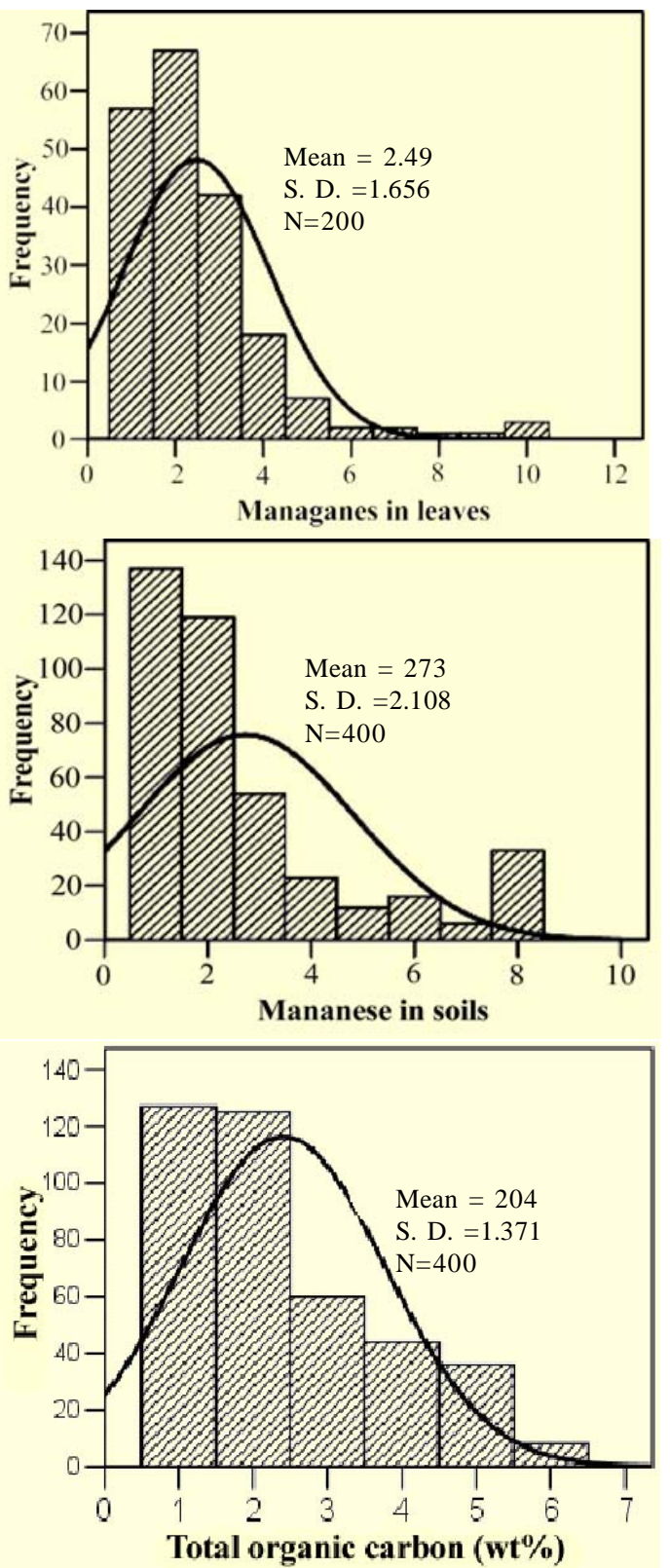

Fig. 1: Histogram with normal curves of manganese in leaves and soils, and TOC of soil samples indicated positive $t$ statistic value (Fig. 3d). Further complementary multivariate analysis of the soil samples using complete linkage hierarchical clustering method and correlation coefficients as a measure of similarity was performed (Fig. 4). The degree of association between groups of variables is represented by the distance axis. The lower the value on the axis, the more significant the association is. Two main hierarchical clustering were obtained.
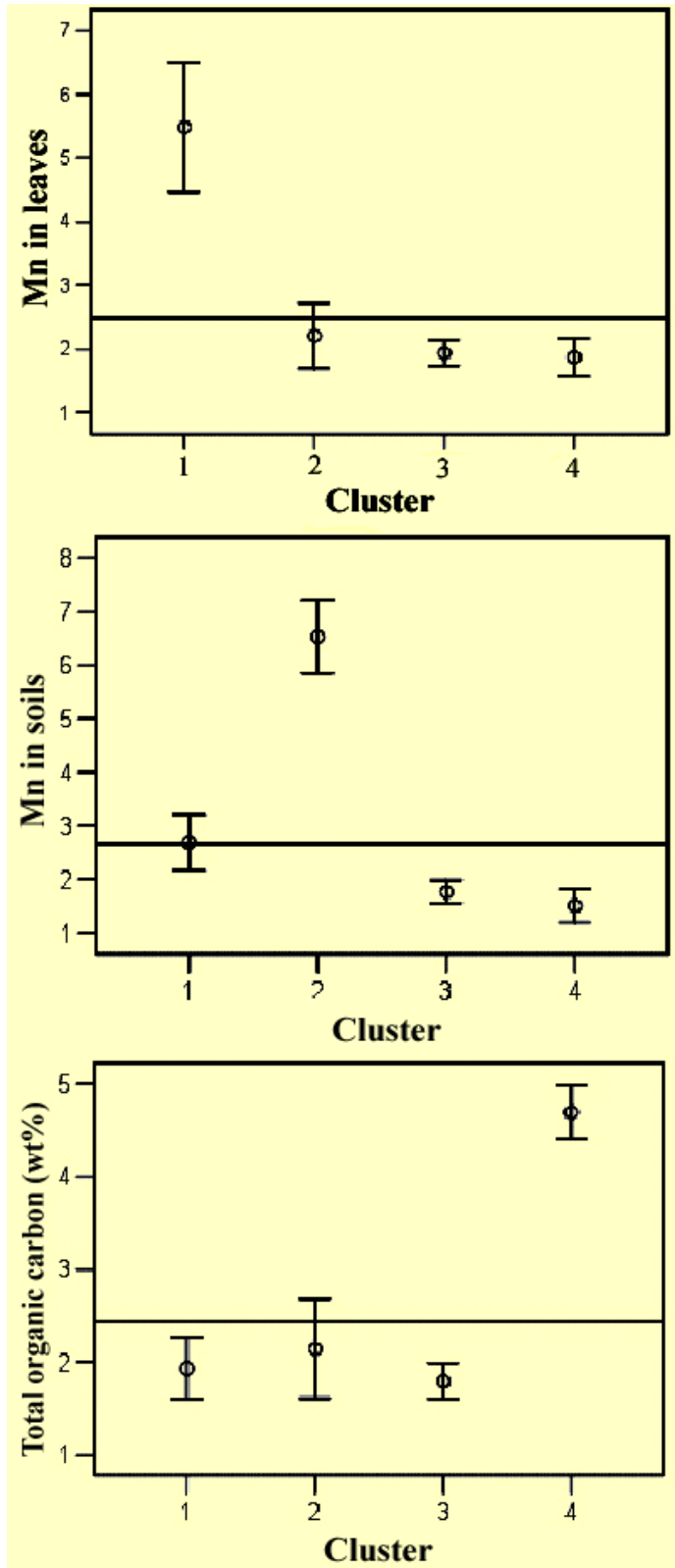

Fig. 2: Simultaneous 95\% confidence intervals for means of manganese in (a) leaves and (b) soils, and (c) TOC of soil samples 

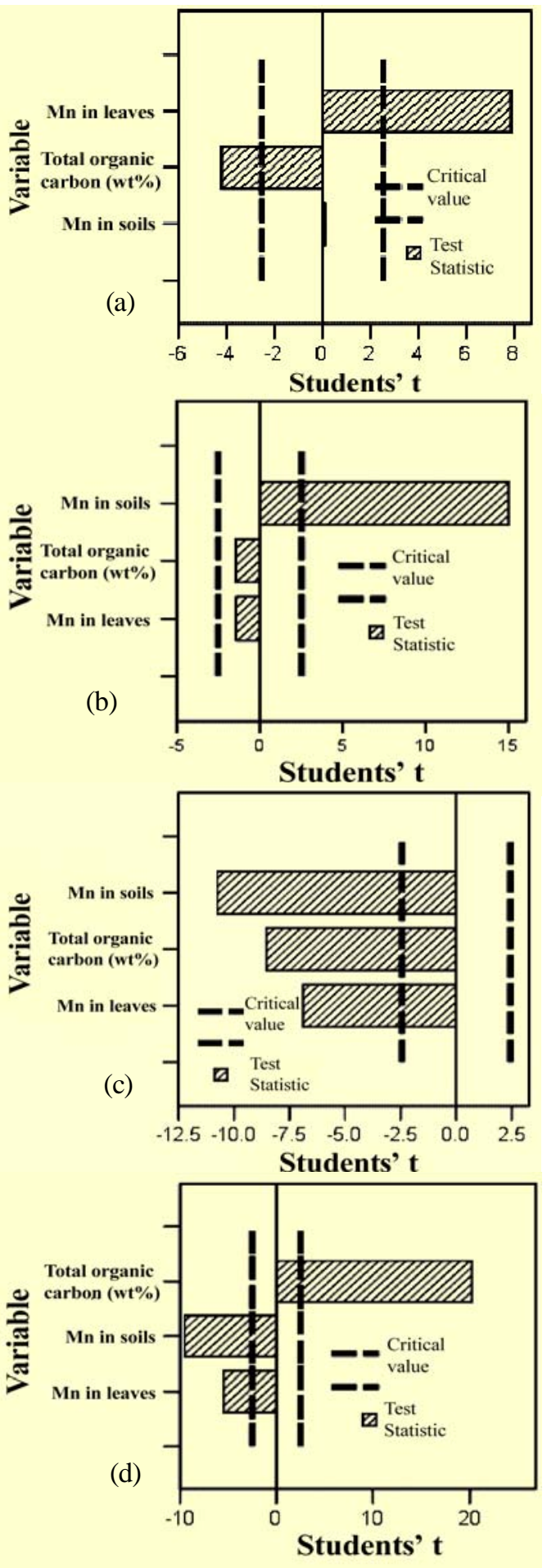

Fig. 3: Bonferroni adjusted two step cluster for $\mathrm{Mn}$ in leaves and soils and TOC of soil samples.
Mn concentrations in leaves and Mn concentrations in soils were very well coordinated followed by the linking of the three parameters by TOC in soils at the end of the distance axis.

\section{DISCUSSION AND CONCLUSION}

Spatial distribution of TOC and vegetation cover

The colours reflected in the non contoured map presented in Fig. 5 as bluish, greenish, yellowish, brownish and reddish colour shades were unevenly spatially distributed and depicted prograded TOC values. Colour gradation in the non contoured map is reflected from blue for the low soil TOC values progressively to green, yellow, brown, red and pink for the high soil TOC values in the study site. From the map, it could be deducted that the TOC values for soil samples are high in the part west of Kgwakgwe Hills and in the central northern part of the study area. Otherwise the TOC values are generally low in the Kgwakgwe Mn mining sites and in the northeastern parts of the map area. High and low are used relatively in this context to distinguish the wt \% of TOC in the soils in the study area; otherwise in general the TOC values are low. The vegetation index values from the image of the study area shown in Fig. 6 range from 0.2 to 0.3 . Quarry sites, roads, houses and bare ground have the lowest values of around less than zero, fields, cleared areas have values around zero. Trees around homesteads, sparse vegetation shows values around 0.1 whilst dense vegetation shows the highest values between 0.2 and 0.3 . Difference in brightness values in the image may have been caused by topographic conditions, shadows or changes in sunlit illumination angles and intensity. These conditions could hamper the ability to identify surface material in a satellite image. A ratio transformation of image data was used to reduce the effect of these environmental conditions. Ratio images were also used for discriminating subtle differences in spectral variations and to eliminate albedo effects and shadows. Vegetated areas have a high reflection in the near infrared and a low reflection in the visible range of the spectrum. Clouds and water on the other hand have larger visual than near infrared reflectance. Rocks and bare soils have similar reflectance in both spectral regions (BRIMP, 2001; Ringrose and Matheson, 1991).Multi band statistics was performed to find the difference between all pixel values and the mean values for each channel i.e. channel variability. Correlation between two or more 
Table 4: Centroids of cluster profiles of manganese in leaves and soils and TOC of soil samples

\begin{tabular}{ccccccc}
\hline Cluster & Mn in leaves & Mn in soils & TOC (wt \%) & & & \\
\hline & Mean & S. D. & Mean & S. D. & Mean & S. D. \\
\hline 1 & 5.48 & 2.046 & 2.69 & 1.039 & 1.93 & .651 \\
2 & 2.21 & 1.149 & 6.53 & 1.502 & 2.15 & 1.184 \\
3 & 1.94 & 0.784 & 1.78 & 0.819 & 1.80 & 0.746 \\
4 & 1.87 & 0.695 & 1.51 & 0.756 & 4.69 & 0.694 \\
Combined & 2.49 & 1.656 & 2.67 & 2.040 & 2.44 & 1.381 \\
\hline
\end{tabular}

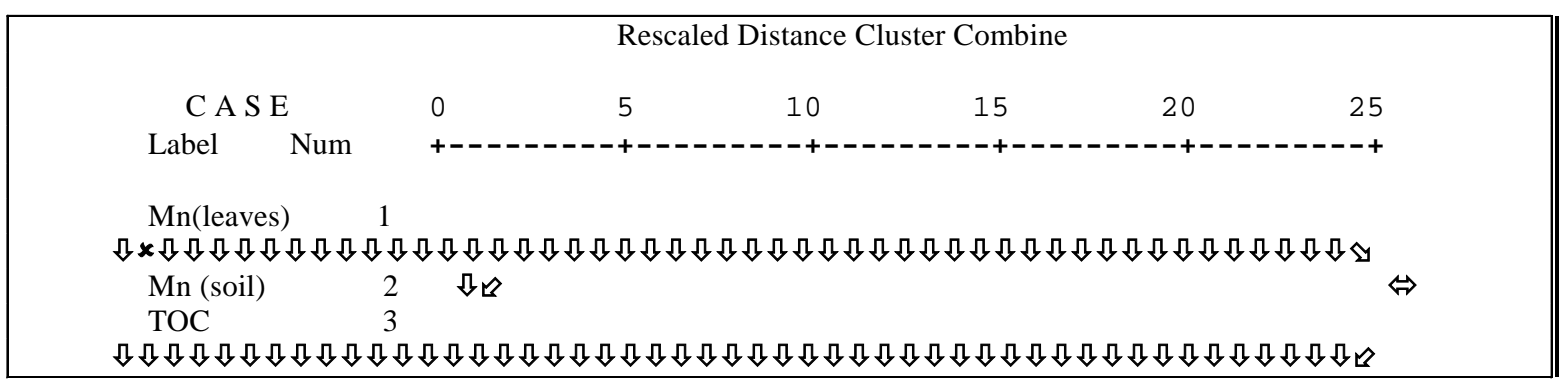

Fig. 4: Dendrogram using complete linkage of manganese in leaves and soils and TOC of soil samples

Table 5: Correlation between bands

\begin{tabular}{ccccc}
\hline Band No & 1 & 2 & 3 & 4 \\
\hline 1 & 1.00 & 0.95 & 0.88 & 0.38 \\
2 & 0.95 & 1.00 & 0.94 & 0.50 \\
3 & 0.88 & 0.94 & 1.00 & 0.40 \\
4 & 0.38 & 0.50 & 0.40 & 1.00 \\
\hline
\end{tabular}

channels is shown by covariance statistics. A correlation matrix was used to evaluate the degree of correlation between individual bands and is as shown in Table 5. The matrix normally has values ranging from -1 to 1 , indicating a strong negative correlation to a strong positive correlation respectively. Each band has a 1.00 correlation with itself as expected otherwise the higher the correlation it implies that there is redundancy in the data as information is being repeated across the two bands. If the value is zero, then there is either no correlation or the correlation is weak. Large positive values are indicative of strong positive correlation, and large negative vales reflect strong negative correlation. Band 1and Band 2, Band 1 and Band 3, and Band 2 and Band 3, show the highest correlation. The NIR (Band 4) and visible bands have the lowest correlation in the order; Band 4 and Band 1, Band 4 and Band 3, Band 4 and Band 2 respectively. The NR shows a highest correlation of 0.5 to band 2 in the visible range. Band combinations with lowest in other words showing more information correlation were bands 4, 1, 3 .

\section{Environmental considerations}

It was observed that the plant leaves changed in colour from light reddish yellow around the mine workings area to green in the valleys and close to settlements. Leaves of plants located at the periphery were more colour affected than others. The peripheral leaves were the first to alter in colour. Where discoloration of leaves occurred, it was noticed that the young leaves started out as green but changed progressively in colour to light reddish yellow and eventually to golden yellow. In areas where Mn oxide ore occurred and/or was mined, either there was no vegetation cover observed or the area was covered with sparse vegetation. In these mine working areas, the plants were stunted and conspicuously shorter than their distant neighbours within the study area and the control site. Mature leaves of plants in areas of darkly coloured soils were between $2 \mathrm{~cm}$ and $2.5 \mathrm{~cm}$ in length compared to areas where soils were light brown to yellow in colour with plants having fresh broad leaves exhibiting full growths both in colour (green) and length $(6 \mathrm{~cm}$ to $7 \mathrm{~cm}$ ). Efforts were made to establish the association of Mn concentrations in soils and vegetation to TOC. Increase in Mn concentrations in soils and leaves corresponded to decrease in TOC in the soils (Fig. 7). This relationship was also statistically demonstrated through clustering. 
More than $60 \%$ of the samples which constituted cluster three had very low TOC. The few samples which constituted cluster one had Mn concentrations in leaves to be between $1200 \mu \mathrm{g} / \mathrm{g}$ and $2099 \mu \mathrm{g} / \mathrm{g}$; and those for cluster two had Mn concentrations in soils to be between $2000 \mu \mathrm{g} / \mathrm{g}$ and $3000 \mu \mathrm{g} / \mathrm{g}$. This demonstrates that the clustering was governed mainly by percentages of TOC and Mn concentrations in soils, and Mn concentrations in leaves. The amount of TOC present in soils is governed by the soil organic matter $(\mathrm{OM})$. Furthermore, the vegetation is the main determinant of OM in soils. However, soil $\mathrm{Mn}$ influences $\mathrm{Mn}$ in leaves (vegetation). The soil $\mathrm{Mn}$ is controlled by the CEC and the CEC by the soil clay fraction mineralogy. At Kgwakgwe, the dominance of 1:1 clay minerals (Ekosse, 2001), and the acidic nature of the soils does not favour exchange sites for Mn ions and as such they remain in solution and are available for plant uptake.In conclusion, this study focused on using multivariate analyses and GIS techniques in understanding the spatial distribution of TOC in soils close to an abandoned manganese mine, and to establish any relationship of with $\mathrm{Mn}$ concentrations in soils and vegetation. Distribution patterns show that where TOC percentages were high, Mn concentrations in soils and vegetation were very low. Four successions of TOC, Mn concentrations in soils and Mn concentrations in vegetation distribution patterns are recognized which could be translated to the four clusters obtained by multivariate analysis. Whereas the TOC values increased with increase in distance from south to north and from east to west of the study area, the Mn concentrations in soils and vegetation on the other hand, decreased for similar longitudinal and latitudinal distances. These patterns correspond to the four clusters obtained statistically: cluster one was dominantly Mn in leaves, cluster two had Mn in soils, and TOC in soils made up the fourth cluster. Cluster three was dominated by the three parameters but with negative t statistic. The results infer to high soil acidity, and soil clay fraction mineralogy to have played an influential role in determining this relationship of soil TOC with $\mathrm{Mn}$ concentrations in soils and leaves.

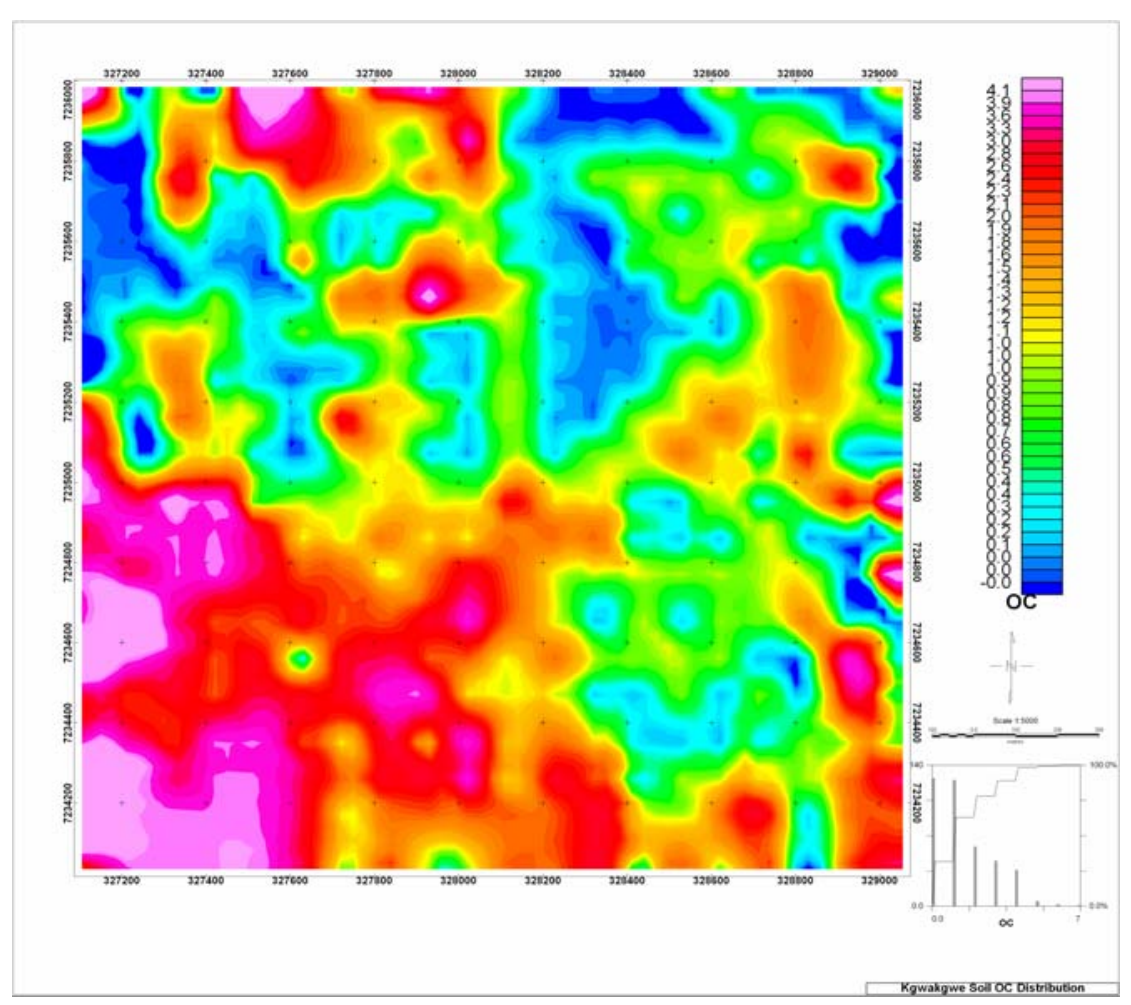

Fig. 5: Non contoured map of spatial distribution of the TOC content in the soils of the studied area 
E. Ekosse, et al.

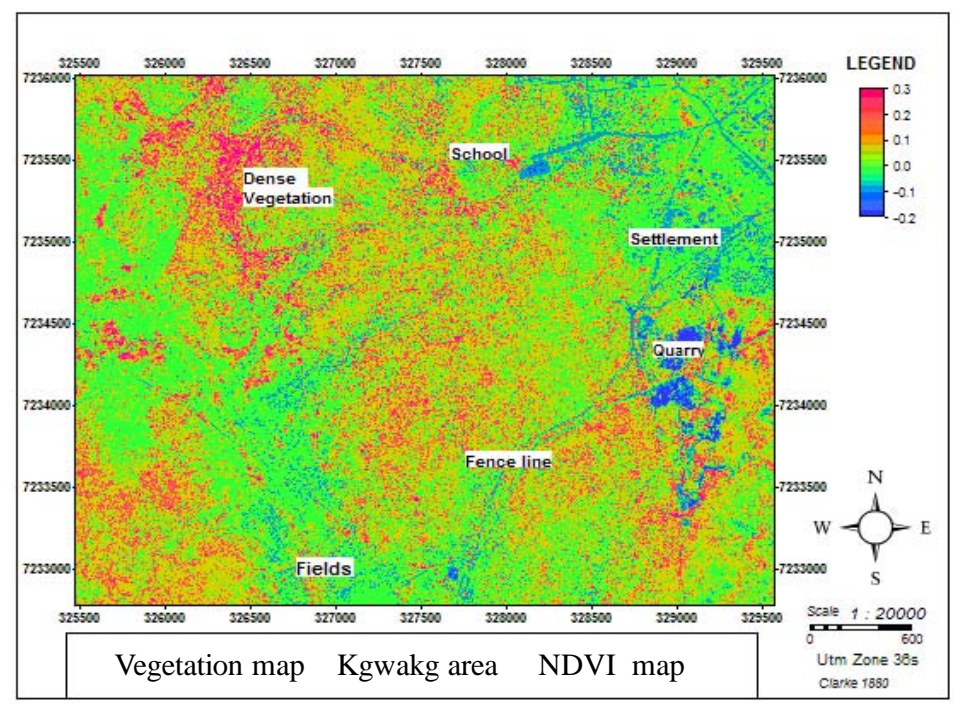

Fig. 6: Normalised difference vegetation index map of the studied area

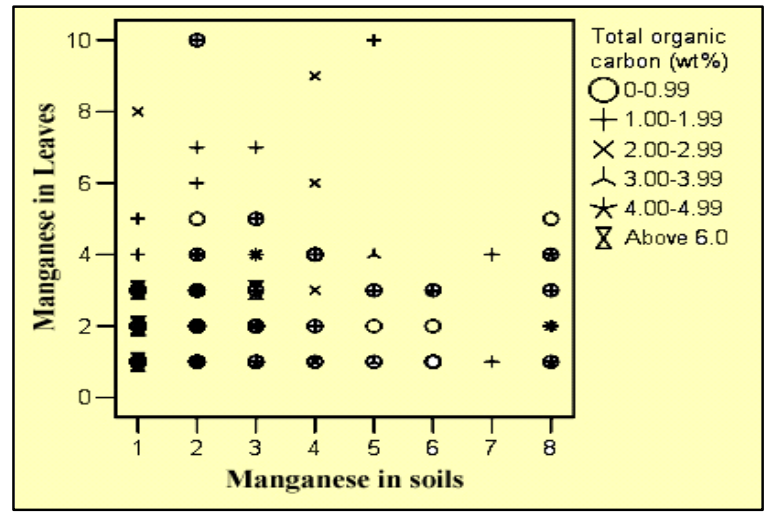

Fig. 7: Normalised difference vegetation index map of the studied area

\section{REFERENCE}

Anonymous, ILWIS 3.0 (2002). Academic User's Guide. International Institute for Aerospace Survey and Earth Sciences (ITC) Enschede, The Netherlands, 530.

Anonymous, (2001)., Botswana Range Inventory Monitoring Project, (BRIMP) Botswana Range Inventory Monitoring Project Phase II: The Biomass Map of Botswana, Growing Season 2000/2001. Ministry of Agriculture, Private Bag 003, Gaborone, Botswana.

Crépin, J. and Johnson, R. L., (1993). Soil sampling for environmental assessment. In Carter R. M. (Ed.) Soil sampling and methods of analyses.

Ekosse, G., (2001). Provenance of the Kgwakgwe

kaolin deposit in southeastern Botswana and its possible utilization. Appl. Clay Sci., 20, 137-152.

Ekosse, G., and Forcheh, N., (2005). A multivariate approach to granulometry of kaolinitic sediments from Botswana. Botswana J. Tech., 14 (1), 35-40.
Ekosse, G. and Fouche, P. S., (2005). Spatial distribution of manganese on Kgwakgwe vegetation cover in the proximity of an abandoned manganese oxide mine and implications for future agricultural development in the region. Land Contamination and Reclamation. 13 (3), 267-273.

Ekosse, G. and Fouche, P. S., (2005). Using GIS to understand the environmental chemistry of manganese contaminated soils, Kgwakgwe, Botswana. J. Appl. Sci. Environ. Manage., 9 (2), 37-42.

Ekosse, G. and Mulaba-Bafubiandi, A. F., (2003). Kaolin occurrences in Botswana and possible uses as functional fillers. Proceedings of the $16^{\text {th }}$ Industrial Minerals International Congress, Montreal, Canada. 6-9 April 2003, 68-80.

Ekosse, G., Ngila, J. C. and Forcheh, N., (2005). Multivariate analyses of heavy metals in soils and Colospermum mopane leaves around the Selebi Phikwe nickel-copper mine and smelter/concentrator plant, Botswana. J. Appl. Sci. Environ. Manag., 9 (1),177-185.

Ekosse, G. and Nkoma, J. S., (2002). Electron microscopy and complementary techniques in the study of kaolinite formation from localised muscovite. Proceedings of the International Conference on Electron Microscopy, Durban, South Africa. ICEM, 15, 1079-1080.

Ekosse, G. and Vink, B., (1998). The Kgwakgwe manganese oxides in the Kanye area, southeastern Botswana - evidence for a shallow aqueous palaeo-environment. Botswana Notes and Records, 30, 147-156.

Ekosse, G. and Vink, B., (2001). The Geology and mineralogy of the manganiferous, ferrugenous and argillaceous sediments in the Kgwakgwe basin, lower transvaal supergroup, Kanye area, Botswana, Botswana J. Earth Sciences, 5, 11-20.

Erdas Imagine, (1992). Field guide $3^{\text {rd. }}$ Ed. Erdas, Inc., 628.

Jewell, M. C., Hensley, P. J., Barry, D. A. and Acworth I., (1993). Site investigation and monitoring techniques for contaminated sites and potential waste disposal sites. In Fell R., Philips T., Gerrad C., (Eds.), Geotechnical management of waste and contamination. 
Jones, J. B. and Case, V. W., (1990). Sampling, Handling and Analyzing Plant Tissue Samples, In; Soil Testing and Plant Analysis, $3^{\text {rd. }}$ Ed., R. L. Westerman, Ed., Soil Science Society of America, Inc., Madison WI, 389-427.

Lanzincka, P., (1992). Manganese deposits in the global lithogenic system: Quantitative approach. Ore Geology Review. 7, 279-356.

Mitchell, A. J. B., (1976). Soil description and analysis from Eastern Botswana. Land Res. Div. Min. of Overseas Dev. Tolworth, England. Supplementary Report \# 6.

Page, A. L., Miller, R. H. and Keeney, D. R., (1982). Methods of Soil Analysis, Part 2. Chemical and Microbiological Properties, $2^{\text {nd. }}$ Ed. America Society of Agronomy Inc., USA.

Principles of remote sensing, (2000). ITC Educational Textbook Series. International Institute for Aerospace Survey and Earth Sciences (ITC) Enschede, The Netherlands, 170.
Reemelwaal, A., (1988). General soil legend of Botswana. FAO/ UNDP/Gov't of Botswana. Field document, BOT/85/11.

Ringrose, S. and Matheson, W., (1991). Classification of Woody Vegetation Cover in South East Botswana Kalahari, Global Ecology and biogeography Letter, 1, 176-181.

Tan, K. H., (1996). Sample preparation. In Dekker M. (Ed.), Soil sample preparation and analysis.14.

Tan, K. H., (1998). Principles of soil chemistry. Mariel Dekker Inc., USA., 521.

Timberlake, J., (1980). Vegetation map of south east Botswana. Ministry of Agriculture, Botswana, Gaborone.

\section{AUTHOR(S) BIOSKETCHES}

Ekosse, G. I. E., PGD, M.Tech., D.Tech., Ph.D., FIScT is a soil mineralogist and the X-ray diffraction scientist in charge of the X-Ray Diffraction Unit, Faculty of Science, Botswana.

Email: GEkosse@ecite.com

Fouche, P. S., D.Sc., is a senior professor of soil science and acting director of the School of Agricultural and Environmental Sciences, University of Limpopo, South Africa.

Email:paulf@ul.ac.za

Mashatola, B., M.Sc., Lecturer in the Department of Soil Science, University of Limpopo and a Ph.D. student in soil science, University of Limpopo, South Africa. Email: boym@ul.ac.za

\section{This article should be referenced as follows:}

Ekosse, G. I. E., Fouche, P. S. and Mashatola, B., (2006). Total organic carbon in soils and its relation with manganese concentrations in soils and vegetation close to an abandoned manganese mine. Int. J. Environ. Sci. Tech., 3 (1), 15-24. 